\title{
Imprinting cultural, ecologia da ação e alunos(as) bolivianos(as) na escola pública
}

\author{
Elaine Teresinha Dal Mas Dias* \\ João Clemente de Souza Neto**
}

\section{Resumo}

Este artigo tem por objetivo a descrição e a análise do comportamento de alunos(as) bolivianos(as) do oitavo ano do Ensino Fundamental II de uma escola pública estadual. Os procedimentos metodológicos, de abordagem qualitativa, efetivaram-se por intermédio de observações de aulas e de HTPCs (Hora de Trabalho Pedagogo Coletivo). Pauta-se, teoricamente, no pensamento complexo e na legislação educacional brasileira. Os resultados indicam que os(as) alunos(as) bolivianos(as) e descendentes são colocados(as) em situação de inclusão excludente, são discriminados(as) pelos corpos docente e discente, e embrenham-se em locais inusuais aos(às) não bolivianos(as) para se afastarem defensivamente. São os(as) melhores alunos(as) e, por este motivo, recebem pouca atenção da comunidade escolar. Conclui-se que a escola abole aspectos fundamentais para a formação humana, fere a legislação, nega a integração cultural e desrespeita a diversidade.

Palavras-chave: alunos(as) bolivianos(as); diversidade; exclusão; pensamento complexo.

* Doutora em Psicologia e Desenvolvimento Humano pela USP e Professora do PPGE - Universidade Nove de Julho - UNINOVE. São Paulo - SP Brasil. <https://orcid.org/0000-0002-4383-5847>.etdmdias@gmail.com

** Doutor em Ciências Sociais, pela PUC/SP e Professor da Universidade Presbiteriana Mackenzie - UPM. São Paulo - SP - Brasil.

<https://orcid.org/0000-0003-3348-8316>.j.clemente@uol.com.br 


\section{Cultural imprinting, ecology of action, and bolivian students inpublic school}

\section{Abstract}

This article aims to describe and analyze the behavior of Bolivian students of the eighth grade of elementary school II of a state public school. The methodological procedures, with a qualitative approach, were carried out through the observation of lessons and HTPC. It is theoretically based on complex thinking and on the Brazilian educational legislation. The results indicate that Bolivian and descendant students are placed in a situation of exclusionary inclusion, are discriminated by teachers and students, and embark in unusual places to non-Bolivians to move defensively away. They are the best students and, for this reason, receive little attention from the school community. It concludes that the school abolishes fundamental aspects for human formation, violates legislation, denies cultural integration and disrespects the diversity.

Keywords: bolivian students; diversity; exclusion; complex thinking.

\section{La impronta cultural, la ecologia de la acción y los estudiantes bolivianos(as) em la escuela pública}

\section{Resumen}

Este artículo tiene por objetivo la descripción y análisis del comportamiento de los/as alunos/as bolivianos/as del octavo año de la enseñanza fundamental II de una escuela pública estatal. Los procedimientos metodológicos, de abordaje cualitativo, se efectuaron por intermedio de observaciones de clases y de HTPC. Se agrava, teóricamente en el pensamiento complejo y en la legislación educativa brasileña. Los resultados indican que los/as alunos/as bolivianos/as y descendientes son colocados en una situación de inclusión excluyente, son discriminados/as por el cuerpo docente y discente, y se adentran en lugares inusuales a los/as no bolivianos/ as para alejarse defensivamente. Son los/as mejores alunos/as y, por este motivo, reciben poca atención de la comunidad escolar. Concluye que la escuela abole aspectos fundamentales para la formación humana, hiere la legislación, niega la integración cultural y transgride la diversidad.

Palabras clave: alunos/as bolivianos/as; la diversidad; exclusión; pensamiento complejo. 


\section{Introdução: Imigração e direitos humanos}

Nos últimos anos a violação dos direitos humanos, as guerras, a busca por trabalho, a desestabilização econômica, a xenofobia, os preconceitos - religioso, de gênero, raça, cor ou etnia - têm marcado o deslocamento de centenas de pessoas que deixam seus países de origem em busca de acolhimento e refúgio em terras próximas ou distantes com a ambição de nelas permanecer definitiva ou temporariamente (IMDH, 2014).

Fenômeno clássico, repetitivo e frequente, as imigrações agregam estados e graus de aceitação ou refusão das populações de países receptores por configurarem-se, no imaginário popular, como usurpadores e um problema de cunho social no plano institucional (CANDAU, 2011), por demandarem uma estrutura organizacional específica e uma teia de amparo receptiva. A ausência desses elementos encaminha a uma concepção de imigrantes como atopos, "[...] Nem cidadão nem estrangeiros, nem totalmente do lado do Mesmo, nem totalmente do lado do Outro, o 'imigrante' situa-se nesse lugar 'bastardo' [...], a fronteira entre o ser e o não-ser social." (BOURDIEU, 1998, p. 11, aspas no original), por ser, em sua maioria, desvalorizados ao chegar inclassificados e, com frequência, indocumentados. ${ }^{1}$ Apesar de marginalizados, discriminados e não esperados, os imigrantes alcançam novos destinos, conduzindo ampla bagagem cultural, experiências de vida, saberes adquiridos, língua materna e o desejo de resgate do seu ser social.

Sayad (1998, p. 54-55) assevera que o imigrante "[...] tem razão de ser pelo trabalho e no trabalho. [...] Foi o trabalho que fez nascer o imigrante, que o fez existir; [...]". Todavia, essa disposição existencial o submete à execução de serviços, eventualmente, rejeitados pela comunidade que os asilou, em invariável posição de subalternidade e de ilegitimidade (MARTINS e VANALLI, 2001).

Segundo Maria Cristina Dadalto (2012, p. 38), o Governo Federal, com a regularização da Lei de Anistia em 30 de dezembro de 2009, "revela que da maioria dos quase 42 mil imigrantes indocumentados residindo no Brasil e que solicitaram visto de permanência provisória, 16.881 é composta por bolivianos" [...]. Disponível em: <http://www.bocc.ubi.pt/pag/dadalto-maria-representacao-social-sobre-imigracao-na-midia.pdf 
No Brasil, o fluxo migratório, se comparado a outras nações, apresenta uma reduzida quantidade de imigrantes, um total de $0,4 \%$, ou 750 mil, em um universo de 207 milhões de habitantes, como atestam os cálculos da Polícia Federal ${ }^{2}$ e da pesquisa empreendida por Ruediger et al. (2015). Não obstante, o Relatório Anual do Observatório das Migrações Internacionais - OBMigra, ${ }^{3}$ de 2019, ao assinalar a quantidade de pessoas vindas de países associados ao Mercosul, mostra que, no período entre 2011e 2018, a Colômbia obteve o maior número de autorizações contempladas, perfazendo um total de 3.179, a Venezuela 3.191 e Peru 3.062. O Anuário de 2018 salienta que os latino-americanos obtiveram $66,8 \%$ das autorizações concedidas, e o de 2017 enfatiza que entre 2010 e 2016 as maiores procedências aqui desembarcadas foram provenientes do Haiti, Bolívia, Argentina, Colômbia e Paraguai, respectivamente.

Neste quadro, a imigração boliviana, foco da pesquisa ora apresentada, distingue-se pelos deslocamentos para o Brasil iniciados na década de $1950 \mathrm{com}$ uma proposta de intercâmbio cultural (SILVA, 2006). Mais tarde, os traslados intensificaram-se em decorrência dos altos índices de desemprego na Bolívia, que encaminhavam o agravamento da pobreza. Afere-se que vivam na região sudeste aproximadamente 350 mil bolivianos aportados e esperançosos por melhores condições de vida, por vezes transformadas em desesperança, porquanto muitos chegam iludidos por promessas de emprego na indústria de confecção, ${ }^{4}$ que na realidade são atividades diárias extenuantes de longa duração, comparadas a um regime de semiescravidão.

Vidal (2012, p. 94) certifica que os brasileiros percebem os imigrantes bolivianos residentes nos bairros Pari, Bom Retiro, Brás e Mooca, como "[...] um povo tranquilo, trabalhador, lutador pela vida [...]", “[...] pessoas que não se metem na vida dos outros [...]",

\footnotetext{
2 Disponível em: < https://www.uol/noticias/especiais/imigrantes-brasil-venezuelanos-refugiados-media-mundial.htm>. Acesso em 26 fev. 2020.

3 Disponível em: <http://obmigra.mte.gov.br/>. Acesso em 17 abr. 2019.

4 Cf. Luiz Eduardo W. Wanderley: a "Bolívia tinha o centro têxtil mais importante do vice-reinado rio-platense" (2008, p. 113).
} 
mas que são [...] "escravos" ou "[...] escravizados". Por sua vez, os bolivianos dizem que "o Brasil é um país muito acolhedor" e que, apesar de sentirem falta de sua terra", as condições de vida e trabalho são muito melhores em São Paulo do que na Bolívia. [...]”.

Oportuno ressaltar que, em maio de 2017, foi instituída no território brasileiro a nova Lei de Migração, sob no 13.445 , dispondo os direitos e deveres do migrante e do visitante. De acordo com o art. $3 \frac{05}{}$ do Capítulo I das Disposições Preliminares, Seção I, Disposições Gerais, a política migratória rege-se pelos seguintes princípios e diretrizes:

I - universalidade, indivisibilidade e interdependência dos direitos humanos; II - repúdio e prevenção à xenofobia, ao racismo e a quaisquer formas de discriminação;

III - não criminalização da migração;

IV - não discriminação em razão dos critérios ou dos procedimentos pelos quais a pessoa foi admitida em território nacional;

$\mathrm{V}$ - promoção de entrada regular e de regularização documental;

VI - acolhida humanitária; [...] (DOU, 2017, s/p.).

No art. 4ㅜ inciso X, do Capítulo I destas Disposições, encontra-se também a recomendação do "direito à educação pública, vedada a discriminação em razão da nacionalidade e da condição migratória; [...]" (DOU, 2017, s/p.), que coincide com o Estatuto de Criança e do Adolescente (ECA) e os Parâmetros Curriculares Nacionais (PCNs), em particular, no que se refere à normatização socioeducacional, às regulações comportamental e atitudinal no encargo da infância e à adolescência.

Assim, o ECA, Lei no 8.069, de 13 de julho de 1990, oficializa, no seu art. 5- das Disposições Preliminares que:

Nenhuma criança ou adolescente será objeto de qualquer forma de negligência, discriminação, exploração, violência, crueldade e opressão, punido na forma da lei qualquer atentado, por ação ou omissão, aos seus direitos fundamentais" (BRASIL. Estatuto da Criança e do Adolescente, 2001, p. 10).

5 http://www.planalto.gov.br/ccivil_03/_ato2015-2018/2017/lei/L13445. htm. Acesso abr. 2019. 
E no seu art. 53, Capítulo IV - Do Direito à educação, à cultura e ao lazer, destacam-se: "I - igualdade de condições para acesso e permanência na escola; II - direito de ser respeitado por seus educadores." (idem, p. 21).

Os PCNs, outrossim, pontuam a importância de um convívio democrático e atenção à multiplicidade de culturas que constituem a sociedade brasileira, indicando que se entende por cultura

[...] toda manifestação que emana das trocas sociais e é transmitida através das gerações. A língua, a música, a arte, o artesanato, entre tantas outras, são manifestações culturais.

A língua, bem cultural e patrimônio coletivo, reflete a visão de mundo de seus falantes e possibilita que as trocas sociais sejam significadas e ressignificadas. [...]" (PCN+, 2002, p. 66).

Prescrevem, ainda, a conquista de comportamentos solidários e cooperativos, que recusem iniquidades, reconheçam aspectos individuais e socioculturais de povos e nações, e a aquisição de posicionamento crítico diante de "[...] discriminação baseada em diferenças de raça/etnia, classe social, crença religiosa, sexo e outras características individuais ou sociais; [...]" (BRASIL, 1997, p. 143).

Frisa-se que a finalidade precípua dos documentos é realçar a diversidade e a etnocultura como fundamentos inerentes às identidades, e que "[...] a educação escolar deve considerar a diversidade dos alunos como elemento essencial a ser tratado para a melhoria da qualidade de ensino e aprendizagem." (BRASIL, 1997, p. 63). No segundo volume dos Temas Transversais, notadamente nas orientações alusivas à Pluralidade Cultural e Orientação Sexual, acentua o reconhecimento a uma convivência democrática ${ }^{6}$ e o respeito à multiplicidade de culturas que constituem a sociedade. Intenciona-se, portanto, que as instituições escolares se pautem nos termos legais para a construção de sentimentos elevados dirigidos a

O termo democracia e suas derivações são entendidos conforme a Constituição da República Federativa do Brasil, 1988, também assim aplicando-se à cidadania. 
outrem e elaborem estratégias para a superação de depreciações e/ ou menosprezos tendo em vista a educação escolar. ${ }^{7}$ Entretanto, situações de relutâncias, oposições e intolerâncias têm sido reveladas em vários estudos (PATTO, 1993, 2005; AQUINO, 1998; HENNING e ABBUD, 2010), gerando ceticismo quanto aos designíos da educação ao delinear traços subjetivos que transpassam o ensino, o aprendizado, as inter-relações e a pessoalidade de docentes e discentes (MARTINEZ, SCOZ e CASTANHO, 2012.

Este panorama ensejou esta pesquisa com alunos imigrantes e descendentes de imigrantes, em particular os bolivianos, na escola pública.

\section{Contexto da pesquisa e procedimentos meto- dológicos}

A escola na qual se desenvolveu a investigação pertence à Diretoria Centro do Estado de São Paulo. Congrega cerca de 1.500 alunos divididos entre os Ensinos Fundamental I e II e o Ensino Médio. Localiza-se em uma área debilitada da região central do município de São Paulo que, apesar de apresentar todos os equipamentos necessários para um desenvolvimento regional sustentável, tem o entorno degradado, com comércios variados e movimento intenso de pessoas. A maioria dos alunos reside em acomodações encortiçadas, trabalha no contraturno ou durante a madrugada e enfrenta situações de alta vulnerabilidade.

Esta pesquisa, de abordagem qualitativa, tem como objetivo a descrição e a análise do comportamento de alunos bolivianos do 8ํano do Ensino Fundamental II, por intermédio de observações semanais em classe e nas áreas comuns. Pauta-se, teoricamente, nas proposições do pensamento complexo de Edgar Morin e na legislação educacional brasileira.

Educação escolar é aqui compreendida como "um investimento intergeracional com o objetivo de inserir os educandos nas forças construtivas do trabalho, da sociabilidade e da cultura". (SEVERINO, 2001, p. 67). 
A explicitação dos objetivos e dos procedimentos metodológicos à direção, à coordenação pedagógica e ao professorado em HTPC facilitou o início dos trabalhos. Apenas dois professores, um de Educação Física e outro de História, aceitaram a presença da pesquisadora em suas aulas. Os alunos, depois de informados sobre a constância e a finalidade da presença da pesquisadora, foram unânimes em aceitá-la.

A problematização concentrou-se nas indagações: (a) Como os professores representam, absorvem e tratam a pluralidade cultural dos alunos bolivianos e descendentes de bolivianos? (b) Como é o desempenho desses alunos em aula? (c) O que revelam observações dos seus comportamentos e atitudes?

\section{Bolivianos e descendentes de bolivianos em uma escola pública}

Principiadas as observações, de modo geral, não somente dos alunos bolivianos e descendentes de bolivianos (daqui em diante denominados $\mathrm{ABs}$ ), atesta-se a sobre/determinação da adolescência pela maioria dos membros da escola, o que significa dizer que se colocam em lugar de superioridade e distanciados. Esta visão carrega a solidificação de conceitos, preconceitos e noções deste tempo como conflituoso e incompreensível, concebendo as identidades como "aborrecentes".

A apreensão reducionista e fragmentada deste período confirma e demarca a juventude como problemática, restringe mudanças e a inclina a agir conforme as expectativas do meio. Além disso, fabrica subjetividades que tendem à inoperância na medida em que obscurecem potencialidades, bloqueiam afetividades e interditam capacidades, realizações e crescimento pessoal. Existe, contudo, a probabilidade de que esta imputação seja vencida e transformada em brechas para o desenvolvimento e o progresso pessoal, pois a

8 Importa destacar que uma busca na Plataforma Capes de teses e dissertações não retornou nenhum estudo referente ao desempenho escolar e à subjetividade de alunos bolivianos e descendentes de bolivianos. 
pluralidade de interações e retroações procedentes do meio em que é promovida a intenção ou a ação "[...] escapa, com frequência, ao controle do ator, provoca efeitos inesperados e, às vezes, até mesmo contrários aos esperados.", como assinala Morin (2005a, p. 301) sobre o processo de ecologização. O autor avalia, ainda, que em "[...] uma mesma crise, adolescentes poderão responder de maneira bastante diferente, uns superarão e sairão fortalecidos, outros sucumbirão ao peso neurótico que os marcará por toda vida" (idem, p. 58).

As observações das HTPCs desvelam posições colidentes dos professores diante dos ABs. Por um lado, são descritos como bons alunos, estudiosos, cumpridores das tarefas, assíduos às aulas, obedientes e disciplinados. Por outro, como pouco asseados, abusados, drogaditos, sedutores. Esses julgamentos estão marcados por imprintings culturais orientados aos imigrantes e fechados a modificações ou à reforma do pensamento. Aliás, de certo modo os professores violam os PCNs ao negligenciar a indicação de uma coexistência democrática dirigida às culturas que compõem nossa sociedade; desconsideram ou creditam pouco desvelo às peculiaridades individuais, sociais e culturais de outras populações; e ao provocar, insuficientemente, a solidariedade e a cooperação com ênfase apenas à negritude.

Violam também o ECA e a Lei de Migração. O primeiro prescreve o cuidado e a atenção a todas as crianças e adolescentes e ressalva seus direitos fundamentais, como o de ser respeitados por seus professores. A segunda abomina a xenofobia, a discriminação em virtude de fatores de admissão, nacionalidade, migrações e hostilidades aos recebidos.

Essas análises estão baseadas em HTPCs quando do debate de dois casos representativos: o abuso sexual sofrido por uma jovem $A B$ e a embriaguez de alguns alunos $A B$ s. As reações dos professores foram surpreendentes ao externar afetos e representações provocados por este grupo, motivando e desencadeando discursos grosseiros, denominando a aluna que sofreu violação "biscateira", e os que ingeriram bebidas alcoólicas como reprodutores do perfil 
alcoolista da comunidade boliviana, reflexo do desgaste pelo trabalho exaustivo que exercem.

Morin (2005b) aposta no imprinting cultural - "marca matricial que estrutura e conforma os pensamentos, as idéias" (p. 118) como formador de um pensamento simplificador e fracionário que registra experiências, aprende com elas e estabelece uma relação de desatenções e desconsiderações que impelem ao desprezo de tudo o que não coincide com as convicções individuais e socioculturais. Na mesma direção, as normalizações dirigem ao fechamento, à incompreensão e à eliminação do diferente.

Aquele que obedece ao imprinting e à norma está inteiramente convencido das verdades nele gravadas e, em conseqüência, do caráter mentiroso ou diabólico das verdades oriundas de outros imprintings (Morin, 2005b, p. 118-19, itálicos no original).

Parte dos professores, em cinco HTPCs, exteriorizou convencimentos acerca dos imigrantes pelo modo depreciativo como a eles referia-se, a despeito de serem os melhores discentes e esboçarem na fisionomia e no discurso um não pertencimento e uma restrição contígua, dando demonstração de que resta aos $\mathrm{ABs}$ a conformação como atopos.

Infere-se que os sentimentos relacionados ao ABs estão reprimidos ou escamoteados, mas que em determinados momentos se libertam da censura, entendida como "função que tende a impedir aos desejos inconscientes e às formações que deles derivam o acesso ao sistema pré-consciente-consciente" (LAPLANCHE e PONTALIS, 1988, p. 99), mas manifestada por expressões desqualificadoras. As tensões culturais no interior das escolas sinalizam a necessidade de humanizar as relações e desconstruir a pedagogia da humilhação ali implicadas.

No pensamento complexo, a noção de sujeito proclama a fusão, a inseparabilidade e a mutualidade entre o $e \boldsymbol{u}$ objetivo e o Eu subjetivo, expõe a concorrência de um duplo em cada um de nós e patenteia a duplicidade sapiens/demens do Homo complexus. Este une 
os opostos, está sob a influência socioambiental, desponta por seus opostos e contrários e ostenta a sapiência humana com a pretensa subjugação da loucura produtora "[...] de delírio, de ódio, de desprezo e daquilo a que os Gregos chamavam a Hybris, a desmedida" (MORIN, 2005c, p. 10).

O barbarismo antropológico humano concentra-se no demens, e, ao ensejar sua ocultação, ensaia uma neutralidade inverossímil que não pode ser extinta porque parte do ser. Para o pensamento complexo, a “[...] ocultação da nossa subjetividade é o cúmulo da subjetividade” (MORIN, 2005d, p. 328).

É ainda possível abarcar as locuções docentes por intermédio dos complexos imaginários: projeção, identificação e transferência. Nesta perspectiva, a projeção de desejos, anseios e angústias prendem-se na figura de uma pessoa, de um objeto ou de um mito, determinando processos identificatórios e a incorporação de valores, sensações e percepções de outrem. Na formulação de Morin, (in PENA-VEGA, ALMEIDA e PETRAGLIA, 2003, p. 90)

[...] a identificação é como uma propensão profunda, por certo nem sempre integralmente efetuada, de um processo introjetivo pelo qual o sujeito sente como subjetivo, pessoal ou próprio o que lhe é exterior ou estranho. [...] Projeção e identificação são transferências de sentido inverso, ligadas, ademais, por transferências recíprocas. (itálico no original)

É imperativo, portanto, um controle permanente de sentimentos e inclinações em sala de aula, por ser esta um locus aberto e propício a trocas inter-relacionais e à frutificação de projeções e identificações. É forçosa também a prevenção à tendência humana segregacionista, que isola e exclui o outro, em especial pela linguagem que presentifica algo ausente, replica e duplica preconceitos, incompetências e inabilidades.

Nessa atmosfera de intolerância, cogita-se que os ABs estariam fadados ao fracasso escolar. Mas o processo de ecologia da ação, que contém um princípio de incerteza, reverteu as circunstâncias desfavoráveis, possibilitou a suspensão de atos e intenções dos pro- 
fessores e de colegas, suscitou resultados imprevisíveis (MORIN, 2005a) e contrariou a ilegitimidade ao se diferenciarem em atitudes e desempenho escolares. Em outras palavras, são disciplinados, mantêm-se atentos, não participam das brincadeiras em sala, não manipulam celulares, sempre têm os livros à mão para a aula e usam uniformes limpos e asseados.

Em relação à especificidade do desempenho escolar nas aulas de História e respeitadas as afirmações de Smith e Strick (2001), nas quais o baixo rendimento nessas dimensões qualifica alunos com desempenho inferior e dificuldades em alguma área do conhecimento, os ABs demonstraram capacidade de leitura e escrita inerente ao ano letivo e à faixa etária, porque não ocorreram hesitações, vacilos ou imperfeições na fala ou na grafia, em contraste aos não $\mathrm{ABs}$ da mesma turma. Embora simplista, conservadora $\mathrm{e}$ controversa, a definição dos autores permitiu uma apreciação objetiva e concreta do desempenho do alunado apreendida na atividade permanente de apresentação de seminários e debates. Todos são fluentes em português e não têm sotaque.

Entende-se que o desempenho escolar congrega uma gama considerável de variáveis intervenientes e interdependentes nos processos de ensino, aprendizagem e de construção do conhecimento que não se restringe a meras dificuldades, mas exige dos alunos certa independência dos docentes e disposição e arrojo no encaminhamento dos estudos (SEVERINO e SEVERINO, 2012). Também nesta concepção os $\mathrm{ABs}$ ultrapassam os não $\mathrm{ABs}$.

Cabe ressaltar que as aulas de Educação Física se concentravam em jogos com bolas na quadra poliesportiva, das quais apenas um $A B$ participava do futebol, nos outros - queimada $e$ voleibol - nenhum AB estava presente. Nas partidas prevaleciam a violência, por efeito de arremessos de proporções exageradas para fins recreativos, que funciona, talvez, como sublimação ${ }^{9}$ para

9 "Processo postulado por Freud para explicar atividades humanas sem qualquer relação aparente com a sexualidade, mas que encontrariam o seu elemento propulsor na força da pulsão sexual. Freud descreveu como atividades 
os não $A B$ s e como uma esquiva ${ }^{10}$ para os $A B s$, fonte da ausência deste grupo.

A sublimação, como pulsão sexual volatizada e dirigida a um novo ponto, é socialmente aceito (LAPANCHE e PONTALIS, 1988), por exemplo, nas competições esportivas; mas a esquiva pode transformar-se em respostas disfuncionais prejudiciais à saúde psicológica (BRANDÃO, 1999). A violência, aqui adaptada à adolescência e ao jogo, está associada a poder, que é predominante e tem o sabor determinante de demonstrar o domínio de um homem sobre o outro (ARENDT, 1985), como constatado.

Outra particularidade dos ABs é a da proximidade entre pares, nos intervalos e durante o almoço, afastados e isolados dos não ABs. Reúnem-se embaixo da escada ou na quadra poliesportiva externa, onde os demais não frequentam. Na sala de aula ficam em carteiras adjacentes e não se comunicam entre si ou com os colegas, a não ser quando chamados pelo professor. Aqui reside uma questão: Excluem-se ou são excluídos?

A resposta a esta pergunta é esclarecida pelas observações. Nos moldes bourdieuanos, os ABs enclausuram-se, possivelmente, porque se sentem ocupando um lugar ilícito, e os não ABs os segregam pelos mesmos motivos, porquanto são estrangeiros e não cidadãos, muito embora seja o lugar que lhes cabe por direito. Exclusão e inclusão são recursivas, pois “[...] o que é produzido e gerado torna-se produtor e gerador daquilo que o produz ou gera" (MORIN, 2002, p. 19), e complementares e interdependentes. A esquiva marca-se como comportamento permanente e autodestrutivo.

É provável que o adolescente $\mathrm{AB}$ carregue o temor da expulsão e da vivência de estabelecer-se em lugar vedado ao

de sublimação principalmente a atividade artística e a investigação intelectual. Diz-se que a pulsão é sublimada na medida em que é derivada para um novo alvo não sexual ou em que visa objetos socialmente valorizados." (LAPLANCHE e PONTALIS, 1988, p. 638).

10 Maria Zilah da S. Brandão afirma que "a esquiva é considerada um comportamento clinicamente relevante, uma vez que seu excesso ou déficit pode gerar outros problemas comportamentais" (1999, p. 179). 
estranho, e, em assim sendo, suas subjetividades estruturam-se no reinado da ambivalência em dois planos. No primeiro, porque muitos são brasileiros, não imigrantes, mas suas presenças os denunciam como estrangeiros e mobilizam reações de amor e ódio mútuos, sabendo que isto pode levar o desprezado a uma condição subumana (MORIN, 2005a). No segundo, à custa de suas reações regidas por processos defensivos, produzidos pelo bloqueio ou reserva em manejar a realidade, e como forma de equilíbrio psíquico que apela para o distanciamento dos provocadores de sofrimentos, angústias e ansiedades (FREUD, 1926/1996; AMARAL, 1995). As subjetividades dos não $\mathrm{ABs}$ abrigam a rejeição dos imigrantes pelas marcas matriciais a que estão assujeitados. Ressalvam-se os achados de Vidal (2012), que se referiu a adultos.

Como assevera Morin (1999), o sujeito não se limita à morfologia ou ao psicológico. Constituiu-se da conjunção entre aparência externa e emocionalidade, como produto de vivências e experiências com o ambiente e com as pessoas próximas e secundárias: pais, professores, parentes, amigos. Contato e relação desenham os contornos identitários e subjetivos arquitetados com vagar, mas nunca finalizados. Neste sentido, a família dos ABs e a comunidade são continentes, ancoram filhos e conterrâneos e resgatam os seres sociais de cada um ao lhes dar amparo suficiente para que cumpram as obrigações escolares e preservem suas peculiaridades socioculturais em uma ética de solidariedade permanentes (MORIN, 2004). Entretanto, a sociedade que os recebeu emite sinais velados e/ou escancarados de reprovação e os predispõem ao desencadeamento de estados de ataque, fuga ou introversão, como se percebeu em alguns ABs.

$\mathrm{O}$ ataque provém de reações extremadas e inconformadas que ocasionalmente ocorrem como resposta a conjunturas específicas, como a de um aluno que não concordou com sua avaliação de desempenho, embora o ECA assegure este direito; ou generalizadas, quando a mobilização da turma se amplifica por alguma razão, como nos debates. A fuga, como via de separação do perseguidor 
e do abandono, direto ou indireto, está no agrupamento sob a escadaria e na quadra externa, que isola sobremaneira e proíbe o ingresso de outrem que não os iguais, típico também da adolescência, mas que neste caso parece voltado à etnia. E a introversão, que procura desviar-se de uma realidade sem valor devido às frustrações dela emanadas, e que compele ao fantasmático (LAPLANCHE e PONTALIS, 1998), como uma jovem que permanecia incomunicável por todo o período de aula, apenas cumprindo as designações estudantis e aguardando o término do período; esta postura, de certa maneira, certifica a necessidade de se apartar de uma realidade escolar sem sentido, despropositada e ilógica, em que o todo está cindido das partes e estas do todo. A esquiva, neste caso, apresenta-se como provável e preocupante, uma vez que a aluna entremostra alheamento excessivo.

A escola na qual se realizou a pesquisa petrifica a tradição. $\mathrm{O}$ professor detém o conhecimento e o aluno deve, preferencialmente, ouvi-lo. "A normalização manifesta-se de maneira repressiva ou intimidatória; cala os que teriam a tentação de duvidar ou contestar." (MORIN, 2002, p. 31). Os ABs calavam-se, e raramente duvidavam.

\section{Considerações finais}

As escolas conservam os mesmos moldes pedagógicos e o poder concentrado no professor há séculos. Nutrem inalteradas a posição, a disciplinarização, as programações, e suprimem aspectos fundamentais para a formação humana, como aprendizagem conjugada, exploração do entusiasmo pelo saber e pelo conhecimento, consentimento à experimentação, expansão rumo às artes intencionando uma formação integral, relacional e emancipadora. E, ainda, invalidam a compreensão, a aceitação e a inserção da diversidade, aí colocado o imigrante, na medida em que a interculturalidade é primordial para as democracias, as sociedades e a humanidade.

Não se trata de ser, meramente, tolerante e admitir a diferença cultural. Trata-se de convicção, opção ética, respeito aos juízos antagônicos, liberdade de expressão, posicionamento contra ações 
discriminadoras e ofensivas, e da conscientização reflexiva, ${ }^{11}$ na qual aprender com outros povos e outras nações liberta de pensamentos etno ou sociocêntricos dominantes e homogeneizantes (MORIN, 2004) e pode auxiliar um aprendizado que leve à transformação.

As respostas às questões norteadoras sugerem que os professores, nas reuniões de HTPCs, ferem a legislação ao destratar a pluralidade cultural dos alunos $\mathrm{ABs}$ ao torná-los transparentes, sem se dar conta desses princípios e externando suas impressões desses alunos. O professor de História não demonstrou atitudes ou comportamentos preconceituosos em suas aulas, mas a transparência era evidente, pois nunca os convocava para quaisquer funções; já o de Educação Física, contudo, ajudou a inserção de um $A B$ no futebol, mas foi a única inclusão realizada.

A inclusão dos $\mathrm{ABs}$ pode ser caracterizada como integrativa à medida que são aceitos na escola, mas excepcionalmente participam como agentes efetivos ou colaboradores nas atividades gerais da instituição, exceção constatada em uma reunião de pais em que um AB integrava o grupo de dança. A ideia é de aproximar as distintas culturas no reconhecimento das diferenças e incentivar as interligações entre direitos humanos e étnicos, que na escola estão desmembrados e acabam por incitar conflitos e competições.

A sugestão que se defende é a de uma educação que encare ensinamentos compreensivos de incorporação da cultura e da diversidade; que vença as barreiras limitantes do crescimento individual e coletivo; almeje a transdisciplinaridade na transversalidade, com abertura de espaços para a admissão, também, de saberes incorporados da realidade dos alunos. A presença do professor em classe pode transcender sua aula se em seu trabalho diário fizer uso do diálogo, como objeto intermediário, tanto relacional quanto de religação de saberes.

11 Recorre-se à definição de Severino (1986, p. 97) na explicitação de conscientização, "[...] entendida como passagem de uma consciência puramente natural para uma consciência reflexiva, de uma consciência em si para uma consciência para si, de uma consciência dogmática para uma consciência crítica $[\ldots]$ ".. 


\section{Referências}

ARENDT, H. Da Violência. Trad. Maria Cláudia Drummond Trindade. Brasília: Universidade de Brasília, 1985.

AMARAL, L. A. Conhecendo a deficiência (em companhia de Hércules). São Paulo: Robe, 1995.

AQUINO, J.G. Indisciplina na escola: Alternativas teóricas e práticas. São Paulo: Summus, 1996.

BOURDIEU, P. Prefácio: Um analista do inconsciente. In: SAYAD, A. A imigração ou os paradoxos da alteridade. Trad. Cristina Murachco. São Paulo: Edusp, 1998.

BRANDÃO, M.Z. da S. Terapia comportamental e análise funcional da relação terapêutica: Estratégias clínicas para lidar com comportamento de esquiva. Rev. Bras. Ter. Comport. Cogn. São Paulo, vol. 1, n. 2, p. 179-87, dez. 1999. Disponível em <http://pepsic.bvsalud.org/scielo.php?script=sci_arttext\&pi$\mathrm{d}=$ S1517-55451999000200007\&lng=pt\&nrm=iso >. Acesso em 16 abr. 2019.

BRASIL. Estatuto da criança e do adolescente. Lei n. 8.096, de 13 de julho de 1990. Lei n. 8.242 de 12 de outubro de 1991. 3. ed. Brasília: Câmara dos Deputados, Coordenação de Publicações, 2001.

Secretaria de Educação Fundamental. Parâmetros Curriculares Nacionais: Apresentação dos temas transversais. Ética. Secretaria de Educação Fundamental. Brasília: MEC/SEF, 1997. Disponível em: <http:// portal.mec.gov.br/ seb/arquivos/pdf/livro081.pdf>. Acesso em: 26 fev. 2020.

Parâmetros Curriculares Nacionais: Introdução aos Parâmetros Curriculares Nacionais/Secretaria de Educação Fundamental. - Brasília: MEC/SEF, 1997. Disponível em: < http://portal.mec.gov.br/seb/arquivos/pdf/livro01.pdf. Acesso em: 26 fev.2020

CANDAU, V.M. Multiculturalismo e educação: Desafios para a prática pedagógica. In: CANDAU, V.M.; MOREIRA, F.A. (Orgs.). Multiculturalismo: diferenças culturais e práticas pedagógicas. 7. ed. Petrópolis: Vozes, 2011.

CAVALCANTI, L; OLIVEIRA, T.; MACEDO, M., Imigração e Refúgio no Brasil. Relatório Anual 2019. Série Migrações. Observatório das Migrações Internacionais; Ministério da Justiça e Segurança Pública/Conselho Nacional de Imigração e Coordenação Geral de Imigração Laboral. Brasília, DF: OBMigra, 2019. 
DADALTO, M.C. A Representação Social sobre a imigração na mídia brasileira Mapeamento e análise dos discursos comunicacionais. Relatório técnico-científico final CNPq. Disponível em: < $\underline{\text { http://www.bocc.ubi.pt/pag/dadalto-maria-repre- }}$ sentacao-social-sobre-imigracao-na-midia.pdf $>$. Acesso em: 26 fev. 2020.

DIÁRIO OFICIAL DA UNIÃO - DOU. Lei de Migração, n. 13.445. Ed. 99. Seção: 1, 2017.

FERNANDEZ, C.C.G. Entre dois países, sonhos e ilusões: Trajetórias de e/imigrantes bolivianos em São Paulo. Tese de Doutorado em História Social. Pontifícia Universidade Católica, São Paulo, 2015.

FREUD, S. Obras completas. Edição brasileira standard. Inibição, sintoma e ansiedade (1926). Trad. sob direção de Jayme Salomão. Rio de Janeiro: Imago, 1996.

HENNING, L.M.P.; ABBUD, M.L.M. Violência, indisciplina e educação. Londrina: Eduel, 2010.

IMDH - Instituto Migrações e Direitos Humanos, 2014. Disponível em: < $\underline{\text { ht- }}$ tps://www.migrante.org.br/imdh/glossario/>. Acesso: out. 2018.

LAPLANCHE, J.; PONTALIS, J-B. Vocabulário da psicanálise. Trad. Pedro Tamen. 10. ed. São Paulo: Martins Fontes, 1988.

MARTINEZ, A.M.; SCOZ, B.J.L.; CASTANHO, M.I.S. (Orgs). Ensino e aprendizagem: A subjetividade em foco. Brasília: Liber livro, 2012.

MARTINS, D.; VANALLI, S. (2001). Migrantes. 4. ed. São Paulo: Contexto, 2001.

MORIN, E. A noção de sujeito. In: SCHNITMAN, Dora Fried. Novos paradigmas, cultura e subjetividade. Porto Alegre: Artmed, 1999.

. O método 4: As idéias, habitat, vida costumes, organização. Trad. Juremir M. da Silva. 3. ed. Porto Alegre: Sulina, 2002.

- Os sete saberás necessários à educação do futuro. Trad. Catarina E. F. da Silva e Jeanne Sawaya. 9. ed. São Paulo: Cortez, 2004.

. O método 5: A humanidade da humanidade. Trad. Juremir M. da Silva. 3. ed. Porto Alegre: Sulina, 2005a.

- O método 6: Ética. Trad. Juremir M. da Silva. 2. ed. Porto Alegre: Sulina, 2005b. 
Cultura e barbárie europeias. Trad. Ana Paula de Viveiros. Lisboa: Instituto Piaget, 2005c.

O Método 2: A natureza da natureza. Trad. Ilana Heineberg. 3. ed. Porto Alegre: Sulinas, 2005d.

PCN+ Ensino Médio. Orientações Educacionais Complementares aos Parâmetros Curriculares Nacionais. Linguagens, Códigos e suas Tecnologias, 2002. Disponível em: <http://portal.mec.gov.br/seb/arquivos/pdf/linguagens02.pdf $>$. Acesso em: jun. 2018.

PATTO, M.H. de S. A produção do fracasso escolar: Histórias de submissão e rebeldia. São Paulo: T. A. Queiroz, 1993.

Exercícios de indignação: escritos de Educação e Psicologia. São Paulo: Casa do Psicólogo, 2005.

PENA-VEGA, A.; ALMEIDA, C. R. S; PETRAGLIA, I. (Orgs). Edgar Morin: ética, cultura e educação. 2. ed. São Paulo: Cortez, 2003.

OBMigra - Observatório das migrações internacionais. Portal da Imigração. Relatório Anual. Disponível em: https://portaldeimigracao.mj.gov.br/pt/destaques-e-novidades/401287-lancamento-do-relatorio-anual-e-do-datamigra. Acesso em: 26 fev. 2020.

OIM - Organização Internacional para as Migrações. Direito Internacional da Migração. Glossário sobre Migração. 2009. Disponível em: <publications.iom. int/bookstore/free/IML22.pdf>. Acesso em: 26 fev. 2020.

RUEDIGER, M.A. et al. Análise e avaliação do desenvolvimento institucional da política de imigração no Brasil para o século XXI. Caderno de Referência. Rio de Janeiro: FGV, 2015. Disponível em: <http://dapp.fgv.br/wpcontent/ uploads/2016/05/Imigracao_Online.pdf>. Acesso em: abr.2019.

SAYAD, A. A imigração ou os paradoxos da alteridade. Trad. Cristina Murachco. São Paulo: Edusp, 1998.

SEVERINO, A.J. Educação, ideologia e contra-ideologia. São Paulo: EPU, 1986. . Educação, sujeito e história. São Paulo: Olho d'Água, 2001.

; SEVERINO, E.S. Ensinar e aprender com pesquisa no ensino médio. São Paulo: Cortez, 2012. 
SILVA, S.A. da. Bolivianos em São Paulo: Entre o sonho e a realidade. Estud. Av. São Paulo, v. 20, n. 57, p. 157-70, ago. 2006. Disponível em: <http:/ /www.scielo.br/ scielo.php? script $=$ sci_arttext\&pid $=$ S0103-40142006000200012\&lng $=$ pt\&nrm $=$ iso>. Acessos em: 28 fev. 2020.

SMITH, C. e STRICK, L. Dificuldades de Aprendizagem de A a Z: Um guia completo para pais e educadores. Porto Alegre: Artes Médicas, 2001.

VIDAL, D. Convivência, alteridade e identificações brasileiros e bolivianos nos bairros centrais de São Paulo. In: BAENINGER, R. Imigração Boliviana no Brasil (Org.). Campinas: Núcleo de Estudos de População-Nepo/Unicamp, Fapesp, CNPq, Unfpa, 2012.

WANDERLEY, L.E.W. A questão social no contexto da globalização: O caso latino-americano e o caribenho. In: BELFIORE-WANDERLEY, M.; BÓGUS, L.; YAZBEK, M.C. (Orgs.) Desigualdade e a questão social. São Paulo: Educ, 3. Ed., 2008. 